\title{
NEGRITUDE EM TEMPOS DE SEGREGAÇÃO: ANÁLISE SEMIÓTICA DE MELANCTHA (1983), DE GERTRUDE STEIN
}

\author{
Yasmine Louro ${ }^{1}$ \\ Diana Barreto Costa ${ }^{2}$
}

\begin{abstract}
Resumo: O presente trabalho resulta de um projeto de pesquisa que visa analisar, sob a perspectiva discursiva, uma novela da obra Três Vidas, da escritora norte-americana Gertrude Stein. Para isso, foi selecionado o conto Melanctha (1983), título homônimo à protagonista. O objetivo da pesquisa é compreender como a obra segmenta os seus personagens por meio de atributos designados a cada um deles a partir de sua etnia. A fundamentação teórica será norteada através da articulação de um diálogo entre os estudos culturais, como Woodward (2000) e teorias feministas de Bell Hooks (1981;2000) e Angela Davis (1982). Para a análise, mobilizamos as contribuições da teoria semiótica nos trabalhos de Barros (2005) e Fiorin (2008). Privilegia-se na análise o modo como a personagem é figurativizada, considerando os recursos sintáticos e semânticos mobilizados pelo enunciador. A transitoriedade que Melanctha realiza entre os supostos benefícios que a sua pele mais clara oferece e a busca constante pela aceitação da comunidade negra na qual vive é o que evidencia o limbo étnico, o entre-lugar, que preenche o cotidiano da protagonista. Como resultados finais, compreendemos que seus personagens não possuem apenas estereótipos raciais que remetem à situação escrava que perpetrou leis e costumes segregacionistas entre os cidadãos, mas, também, utilizou-se de representações pós-escravidão em que foram submetidos negros e negras pela população branca, expondo-os a situações tão revoltantes e subumanas quanto à escravidão que viveram outrora.
\end{abstract}

Palavras-chave: Melanctha. Gertrude Stein. Representação. Identidade. Semiótica.

\section{Introdução}

É considerado um mistério as razões pelas quais Gertrude Stein desenvolveu a novela Melanctha, presente no livro intitulado Três Vidas, que narra sobre a vida de uma jovem mulher negra suburbana, nos Estados Unidos do início do século XX, quando a mesma vivia expatriada na França, sendo uma mulher branca de classe média (MALCOLM, 2008).

É certo que os críticos de sua obra observaram que havia um fascínio de Stein pela classe média e os seus hábitos e pela construção da nova representação da mulher que se estabelecia no século XX. $O$ ato de haver escrito com tanta precisão a respeito de um assunto que desconhecia - a subjugação feminina de gênero e de raça que sua protagonista enfrenta - , até os dias atuais intriga a sociedade literária e os seus estudiosos, que, mesmo a autora utilizando-se de estereótipos eugenistas (ENGLISH, 2005), conseguiu marcar a sua obra com a proposta ousada para o seu

\footnotetext{
${ }^{1}$ Mestranda em Teoria, Crítica e Comparatismo pela Universidade Federal do Tocantins - UFT. Graduada em Letras Licenciatura em Língua Portuguesa, Língua Inglesa e Literaturas pela Universidade Estadual da Região Tocantina do Maranhão - UEMASUL.

2 Professora Adjunta III, na Universidade Estadual da Região Tocantina do Maranhão - UEMASUL, no Curso de Letras Licenciatura em Português, Inglês e Literaturas, no Centro de Ciências Humanas, Sociais e Letras, do Campus Imperatriz/MA.
}

Revista de Letras JUÇARA, Caxias - Maranhão, v. 03, n. 02, p. 173 - 187, dez. 2019 | 173 
período, pois, o início do século XX foi marcado pela luta do crescente movimento feminista e, principalmente, dos direitos civis nos Estados Unidos (DAVIS, 2016).

De acordo com Silva, Lago e Ramos (1999), a experiência é um processo histórico de construção do sujeito, sendo este implicitamente exposto à condição de existência limitada anteriormente definida, assim como estabelecem que os sujeitos são constituídos a partir do discurso, tendo a história como o meio onde a linguagem é trabalhada. Portanto, a construção da branquidade, definida como características impostas a grupos não-brancos como padrões de comportamento social (WARE, 2004), ao longo da novela, é o que impõe o questionamento à protagonista homônima, Melanctha, se a sua negritude é suficiente para que haja aceitação na comunidade onde vive, desde que, em sua árvore genealógica, existe a presença de sangue branco, apesar de seus pais serem negros.

Portanto, entender os signos utilizados para a construção simbólica do ambiente construído para seus personagens é relevante, desde que "os valores e ideologias contribuem principalmente para o conteúdo, enquanto as modalidades de comunicação influem na forma" (CANDIDO, 2006, p. 39, grifo do autor). A construção discursiva da novela é baseada na sobreposição de signos, pois, para Lucarelli (2013, p. 2), "palavras sobrepõe palavras, formando uma superficial cadeia de intenções". Assim, pretende-se indicar como o narrador expõe o suposto combate que ocorre no interior de Melantcha, por ser uma mulher negra de pele clara em uma sociedade onde não havia meio termo para etnias.

Nesse período, a eugenia tentava conquistar adeptos por prontificar-se a limpar as etnias e mantê-las uniformes, assim como indicar padrões comportamentais por meio da segregação étnica. A descrição narrativa dos personagens negros e daqueles que o narrador alcunha de "mestiços" é familiar à postura adotada por pessoas brancas do início do século XX.

Sendo assim, enquanto a escravidão era mantida sobre pilares de dominação racial e sexual, a população branca e dominante deu início à construção de mitos para segmentar e segregar ainda mais os negros. Para os homens negros, a alcunha de bestiais, considerando que supostamente possuíam "compulsões sexuais irresistíveis e animalescas" (DAVIS, 2016, p. 186); para as mulheres negras, séculos de estupros seguidos resultaram em uma negligência com o próprio corpo, passando a enxergarem-se tal qual o Sul a via, como uma mulher promíscua e fácil (DAVIS, 2016). 
Esses mitos sobrevivem até o século XXI, mas, no início do século $X X$, causaram estragos indeléveis por impossibilitar a entrada de mulheres negras no mercado de trabalho formal, como professoras, ou restringindo-as ao serviço doméstico enquanto babás, cozinheiras ou diaristas.

Desse modo, é relevante compreender como uma personagem negra de tez clara é descrita e sugerida durante a narrativa, com o enfrentamento do estigma o qual a afasta de sua comunidade por torná-la diferente, portanto, o que torna a sua reafirmação enquanto negra em na comunidade que tenta invalidá-la por sua falta de fenótipos, racialmente, compreendidos como negroides, essencial para o clímax narrativo, pois "os fatores sociais atuam concretamente nas artes, em especial na literatura" (CANDIDO, 2006, p. 46).

O presente artigo é apresentado em três seções, sendo a primeira, Percurso metodológico, apresenta a metodologia da pesquisa, a semiótica; a segunda, Melanctha (1983), explora as idiossincrasias acerca do período e da autoria da obra; a terceira seção, Uma comunidade segregada, analisa os aspectos sintáticos do corpus.

A presente pesquisa fora norteada pelos estudos de Davis (2016) sobre gênero e raça, assim como os estudos de English (2004) sobre a obra de Gertrude Stein sob a perspectiva racial e Karnal (2007) sobre a historicidade dos Estados Unidos. A respeito de representação e identidade, Chartier (1991) e Woodward (2000) fizeramse essenciais; sobre teoria da branquidade, que dita os comportamentos de pessoas não-brancas controlados pela ideologia branca, utilizou-se Ware (2004); e Souza (2007) sobre os preceitos do entre-lugar.

\section{Percurso metodológico}

A semiótica, também conhecida como a ciência dos signos, tem como objetivo reproduzir e/ou traduzir representações construídas socialmente. Conforme Barros (2005), a semiótica "tem por objeto o texto, ou melhor, procura descrever e explicar o que o texto diz e como ele faz para dizer o que diz"; ou seja, por meio da semiótica obtém-se as ferramentas necessárias para explorar e identificar, no texto, o que o narrador deixou subentendido. 
Portanto, a semiótica prioriza o exame dos procedimentos de organização textual e dos mecanismos enunciativos, de produção e recepção do texto, o que a torna uma teoria a ser compreendida como a busca dos sentidos do texto por meio do exame de seu plano de conteúdo (BARROS, 2005).

A metodologia é embasada na semiótica estruturalista de Greimas, que busca fundamentar o estudo dos signos mediante o percurso gerativo de sentido (BARROS, 2005). Sendo a narrativa, para Greimas, um discurso expresso de forma figurativa, é utilizado, primeiro, o quadrado semiótico de Greimas (quadro 1) para identificar um denominador comum entre dois termos, sendo, nessa pesquisa, branco x negro. Tal processo é enquadrado no nível fundamental, pois, posteriormente, a partir da seleção dos vocábulos que mais aparecem na narrativa, pode-se obter material para a realização da análise por meio da asserção e da negação, desde que os elementos das oposições semânticas fundamentais sejam assumidos como valores por um sujeito e circulam entre e graças às ações deles (BARROS, 2005).

Após determinado o vocábulo que simboliza o denominador comum, foi-se realizada a primeira etapa do percurso gerativo de sentido - a das estruturas fundamentais -, com o objetivo de obter a significação como uma oposição semântica mínima (BARROS, 2005). Ao longo da narrativa de Melanctha (1983), constrói-se as ideias por meio da repetição, logo, partindo da análise das expressões repetidas ao longo do texto, assim como das palavras repetidas na descrição das personagens, pretende-se obter o sentido proposto pelo narrador no nível discursivo fundamental.

\section{Melanctha (1983)}

A protagonista da novela homônima, Melantcha, é construída de maneira aparentemente singela, como uma moça sem pretensões, sem ambições, que deseja apenas explorar os divertimentos que pode obter da vida. Gertrude Stein, porém, foi uma mulher além do seu tempo, que não se satisfez com uma graduação em Medicina no John Hopkins Medical School, mas soube utilizar as informações obtidas entre plantões, com seus pacientes, para construir três novelas que refletiam não apenas sobre a condição feminina no início do século XX, mas também sobre a luta de classe e raça. 
Obviamente Stein não teve o reconhecimento que sua obra exigia, assim como não reconheceu a análise social que realizou em seu primeiro livro (MALCOLM, 2008). Porém, a semelhança entre personagem e criador, entre Melanctha e Stein, reside justamente nas subversões que as duas realizaram em sua trajetória: Melanctha, enquanto anônimo, e Stein, enquanto influência expatriada na Paris dos anos 1920.

Para Davis (2016, p. 181), entretanto, "até mesmo Stein descreveu uma de suas personagens negras como possuidora da 'simples e promíscua imoralidade do povo negro'”. Aparentemente sem conhecimento aprofundado sobre a situação do cidadão negro estadunidense, Stein construiu uma narrativa ausente de aspectos racistas explícitos, tais como espaços segregados, e sem explicar a origem "mestiça" de seus personagens, desde que o casamento inter-racial era ilegal no período de publicação da obra (WARE, 2004). A construção racial na narrativa é reforçada por meio de adjetivos que segregam os personagens negros daqueles que possuem pele mais clara, alcunhados de mestiços, divididos entre adjetivos socialmente negativos ou positivos.

O atual estudo sobre branquidade, portanto, auxilia na compreensão do que o narrador buscava incluir ao longo da narrativa, inserindo valores brancos no cotidiano da comunidade negra. De acordo com Ware (2004, p. 320), "as denominações de pessoas e grupos com base na nação/classe/etnicidade/raça a que possam revelarse concernentes à branquidade", logo, a prática de definir a origem de personagens não-brancos, tais quais os da novela Melanctha (1983), ou agregar-lhes características que possuem valor na supremacia branca vigente no período no qual a novela foi escrita é a tentativa de dar vantagem estrutural àqueles que se encaixam no padrão e segregar os que não se encaixam.

O primeiro esboço do que viria a se tornar Melanctha (1983), a obra conhecida como Q.E.D. foi escrita ainda no período em que Stein estudava em Harvard e atuava na ala obstetra do John Hopkins Medical School. Naquele momento, Stein alimentava uma paixão tórrida por uma colega mais velha, um romance frustrado que serviu apenas para que a veia artística de Gertrude aflorasse. As personagens centrais de Q.E.D., uma mulher mais velha apaixonada e uma adolescente, foram adaptadas para Melanctha com as personagens Jane Harden, a mulher mais velha da novela, e a protagonista homônima substituindo a adolescente. 
O caráter autobiográfico das obras de Gertrude Stein não é uma temática inédita nos estudos sobre seus personagens. O seu livro mais extenso, The Making of Americans (1925) foi baseado nas experiências de Stein com a sua própria família, os conflitos da narrativa são apenas adaptações de situações testemunhadas por ela ao longo de seu convívio com os parentes.

Em Três Vidas (1983), no entanto, as duas novelas sobre as domésticas de origem alemã são baseadas em uma só mulher: Lena, sua diarista alemã no período em que estudava em Radcliffe. Enquanto $A$ doce Lena teve apenas seu nome como inspiração, $A$ boa Ana foi construída sobre a sua biografia.

Porém, quando o assunto é Melanctha (1983), são inegáveis as semelhanças entre criador e criatura; Melanctha Herbert foi continuamente caracterizada como extremamente inteligente, como alguém superior em sua comunidade, assim como Stein viu a si própria durante toda a sua vida. Outra semelhança é a aparente apatia de Melanctha em continuar o que começa, pois, como repetido, diversas vezes na novela, ela está sempre em busca de novos estímulos. Em $A$ autobiografia de Alice $B$. Toklas (1933), é descrito o momento no qual Stein é chamada ao escritório de um de seus professores para que seja oferecida a ela uma oportunidade de concluir os seus estudos em Psicologia. No momento, Stein afirma que possuía tanta inércia que, caso não houvesse sido chamada, nunca procuraria conclui-lo (STEIN, 2009). Na verdade, ela nunca chegou a conseguir o diploma, desde que perdeu o interesse, de fato, no mundo acadêmico e mudou-se para Paris com o seu irmão, logo após aquela reunião.

$\mathrm{Na}$ dinâmica do relacionamento lésbico retratado em Q.E.D. e resgatado em Melanctha (1983), Stein é a adolescente que acredita que pode aprender com o amor da mulher mais velha. Porém, em Melanctha (1983), Stein retrata o relacionamento de forma singular, pois constrói a dinâmica como se fosse Melanctha quem possuísse todo o poder, relegando a Jane Harden a frustração de, além de não controlar Melanctha, submeter-se às migalhas de afeto e ao consequente abandono quando a jovem mulher acredita ter obtido todo o conhecimento que acreditava procurar.

Segundo Abreu (2008), uma forma de Stein adaptar o método de composição de Cézanne foi substituindo o padrão geométrico por atributos que totalizam a personalidade das personagens, por meio da manifestação consciente de comportamento. 
Em Três Vidas (1983), porém, como protagonistas, Stein optou por desenvolver personagens com um "conhecimento limitado de língua inglesa", incluindo Melanctha, estadunidense. Para Abreu (2008), ao utilizar-se de tal drama, Stein realiza uma denúncia sobre a arbitrariedade da linguagem, que deveria ser um mecanismo transparente de comunicação.

As três novelas de Três Vidas (1983) são ambientadas em uma cidade fictícia, Bridgepoint, supostamente localizada no Sul dos Estados Unidos. As duas novelas responsáveis por narrar a vida das protagonistas imigrantes, as alemãs $A$ boa Ana e A doce Lena, não apresentam convívio com pessoas negras, nem mesmo a menção a um transeunte na rua. É apenas em Melanctha (1983) que o leitor tem contato com a parte negra da cidade. Além do mais, ambas as novelas agregam adjetivos positivos às suas protagonistas, enquanto que, em Melanctha (1983), é apenas intitulado com o nome da protagonista.

A narrativa desenvolve-se a partir da diferença que Melanctha representa na comunidade negra que vive; inicialmente, é apenas a sua pele mais clara a razão do suposto incômodo, porém, ao longo da apresentação de sua infância e adolescência, o narrador indica que os seus hábitos e relações sociais, além de incomuns, eram mal vistos para uma mulher, naquele período. Mesmo que sua pele clara representasse um privilégio em meio à comunidade negra, pois, "a branquidade é um lugar de vantagem estrutural nas sociedades estruturadas na dominação racial" (WARE, 2004, p. 312), suas atividades consideradas imorais, tais como a aproximação com o cocheiro John, quando menina, ou o affair com Jane Harden, uma mulher mais velha, escandalizavam a comunidade na qual vivia sob os preceitos do moralismo branco. Somente a partir disso os negros poderiam obter respeito, desde que "a branquidade é atravessada por uma gama de outros eixos de privilégio e subordinação" (WARE, 2004, p. 312), portanto, o machismo seria uma ferramenta de exclusão, assim como a homofobia.

Esses comportamentos excludentes, como a constante tentativa de Rose de "acalmar" Melanctha, são respaldados pelo viés religioso, pois as duas encontraramse pela primeira vez na igreja e voltaram a se encontrar quando Melanctha, atormentada pelo homem que achava que amava, Jeff Campbell, procurou novamente a Deus, "Melanctha Herbet, quando chegara no auge da crise com Jeff Campbell, 
começara a frequentar aquela igreja onde encontrara Rose pela primeira vez, a qual iria casar mais tarde, regularmente, com Sam Johnson" (STEIN, 1983, p. 183).

A narrativa coloca Rose como o oposto de Melanctha, um exemplo a ser seguido pela protagonista para encaminhar-se para a decência e moralidade, utilizando-se da religião para obtenção de respeito social, mesmo que não acreditasse nisso:

\begin{abstract}
Rose Johnson e Melanctha Herbert conheceram-se, uma noite, na igreja. Rose Johnson não se interessava muito por religião. Não era suficientemente emotiva para que as cerimônias religiosas pudessem impressioná-la muito. Quanto a Melanctha Herbert, ainda não havia aprendido a valer-se da religião. Contudo, ambas, como é costume entre os negros, iam com frequência à igreja negra acompanhadas de todos os seus amigos (STEIN, 1983, p. 85).
\end{abstract}

É tanta a legitimidade religiosa buscada pelo narrador para corroborar os eventos da vida de Melanctha que, diferente das outras duas narrativas, Melanctha (1983) possui como subtítulo - "Cada qual como Deus fez". Sendo assim, o narrador tenta justificar a partir da assimilação religiosa que, além de incorreta, Melanctha seria incapaz de mudar de vida, pois "Deus a fez assim".

De acordo com Milton A. Cohen (apud Gale, 1999, p. 14), "in Stein's effort to make use of William James's theories of basic personality types, she assumes connections among racial heritage, skin color and inborn character traits" 3 . É, portanto, baseado em estudos eugenistas que o narrador encontra o seu pilar argumentativo para desenvolver personalidades controversas.

Nas novelas das alemãs não há uma tentativa de invalidá-las enquanto indivíduos não-estadunidenses, mas em Melanctha (1983) são recorrentes falas que contestam a legitimidade de sua etnia, seja por "ter sangue branco", como afirmam incessantemente os negros, seja por ser negra, como afirmam os brancos.

Além do mais, o desinteresse de Melanctha na espiritualidade, a falta de conexão dela com a fé e a sua sede por aprendizado - caracterizado inicialmente como a necessidade de dialogar com todos que pudessem ensiná-la a viver e, posterior e subjetivamente, a iniciação à descoberta de sua sexualidade -, são similares à trajetória de Gertrude Stein no mundo, desde que sentia-se confortável

\footnotetext{
3 "No esforço de Stein fazer uso das teorias de tipos básicos de personalidade de William James, ela deduz conexões entre herança racial, cor de pele e traços inatos de personalidade." (tradução livre)
}

Revista de Letras JUÇARA, Caxias - Maranhão, v. 03, n. 02, p. 173 - 187, dez. 2019 | 180 
ouvindo às mais diversas personalidades que conviviam na sua casa, em Paris, e apesar de judia, nunca mencionou a religião como parte ativa de sua vida.

Com a obra apresentada, poder-se-á prosseguir para a análise do nível fundamental.

\section{Uma comunidade segregada}

Melanctha Herbert, protagonista da novela homônima de Três Vidas, possui prestígio na comunidade onde vive por ser uma negra de tez clara. Pela suposta diferença representada por ela, o narrador a utiliza como centro de discussão sobre raça, desde que fornece ao leitor a perspectiva de que é privilegiada por não ser retinta. É a partir da descrição realizada pelo narrador que pode-se obter conhecimento do que se deduzia sobre pessoas negras, sendo elas retintas ou claras, sob a perspectiva branca.

De acordo com Barros (2005), uma categoria semântica fundamenta-se em uma diferença, em uma oposição, daí dizer-se que a compreensão gerada pelo nível narrativo fundamental depende da construção discursiva sobre pilares opostos. $\mathrm{Na}$ narrativa explorada, é nítida a polarização negro x branco com o agregar de adjetivos positivos ou negativos de acordo com a etnia das personagens, como bem acontece com Rose, que "era descuidada e preguiçosa, mas fora criada por gente branca" (STEIN, 1983, p. 84), nesse contexto percebe-se que há uma ligação com brancos para "melhorar" o seu status. Portanto, na primeira fase da análise, serão explorados os signos atribuídos às personagens e como tal atribuição implica no campo discursivo.

Como mencionado anteriormente, Melanctha (1983) possui a polarização negro x branco, uma comparação explícita não apenas dos costumes, mas do caráter de representantes desses grupos étnicos presentes na narrativa. A definição presente no Dicionário dos Símbolos afirma que "a dualidade do negro x branco é, de um modo geral, a da sombra e da luz, do dia e da noite, do conhecimento e da ignorância, do yin e do yang, da Terra e do Céu" (CHEVALIER, 1993, p. 742), enquanto signos

atribuídos às cores. É, portanto, verossímil afirmar que a linguagem constrói automaticamente, mediante discurso há muito naturalizado, signos de teor negativo 
para ideias relacionadas à cor preta e signos positivos para ideias relacionadas à cor branca.

Dessa forma, para a análise da narrativa, euforia, isto é, o aspecto positivo da narrativa, configura branco; e disforia, o aspecto negativo da narrativa, configura negro, como observados no quadro 1.

Quadro 1 - Quadro Semiótico com relação de contradição para a semiótica.

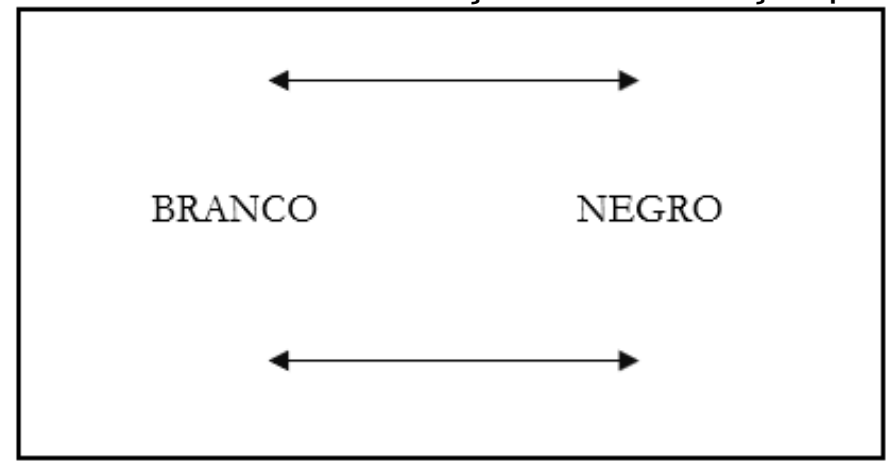

Fonte: Autores (2019).

Após seleção de semas atribuídos às dez personagens nominadas na narrativa, foram observadas as repetições ocorridas no texto para construção de sentido e, a partir disso, delimitados sete semas com maior presença na obra, sendo estes $\mathrm{S}_{1}$ suave, $\mathrm{S}_{2}$ agradável, $\mathrm{s}_{3}$ vulgar, $\mathrm{s}_{4}$ decente, $\mathrm{S}_{5}$ rude, $\mathrm{s}_{6}$ vigoroso e $\mathrm{S}_{7}$ forte, como pode ser observado no quadro 2.

Quadro 2 - Análise sêmica de Melanctha (1983).

\begin{tabular}{|c|c|c|c|c|c|c|c|c|c|c|}
\hline & \multicolumn{10}{|c|}{ ANÁLISE SÊMICA } \\
\hline & $\begin{array}{c}\text { MELANCTH } \\
\text { A }\end{array}$ & ROSE & SAM & $\begin{array}{c}\text { JAME } \\
\mathrm{S}\end{array}$ & $\begin{array}{l}\text { "MIS" } \\
\text { H. }\end{array}$ & JOHN & $\begin{array}{c}\text { JAN } \\
\text { E }\end{array}$ & JEFF & $\begin{array}{c}\text { MÃE } \\
\text { DO } \\
\text { JEFF }\end{array}$ & JEM \\
\hline $\mathrm{S}_{1} \mathrm{SUAVE}$ & $\mathrm{x}$ & & & & $\mathrm{x}$ & & & & $\mathrm{x}$ & \\
\hline $\begin{array}{c}\mathrm{S}_{2} \\
\text { AGRADÁVEL }\end{array}$ & $\mathrm{x}$ & & & & $\mathrm{x}$ & $\mathrm{x}$ & & & & \\
\hline $\mathrm{S}_{3}$ VULGAR & & $\mathrm{x}$ & & $\mathrm{x}$ & & & & & & \\
\hline $\mathrm{S}_{4} \mathrm{DECENTE}$ & & $\mathrm{x}$ & $\mathrm{x}$ & $\mathrm{x}$ & & $\mathrm{x}$ & & & & $\mathrm{x}$ \\
\hline $\mathrm{S}_{5} \mathrm{RUDE}$ & & $\mathrm{x}$ & & $\mathrm{x}$ & & $\mathrm{x}$ & & & & \\
\hline VIGOROSO & & & & & & & & & & \\
\hline
\end{tabular}


Fonte: Autores (2019).

Dessa forma, os sentidos de complementaridade e contradição foram sugeridos na narrativa pela quantidade de vezes que foi repetido pelo narrador ao atribuí-los aos personagens. No caso, s1 suave e s2 agradável foram os semas com maior atribuição e valor agregado pelo narrador, com significado positivo; foram relacionados àqueles que o narrador indicou possuir sangue branco. Logo, os semas com maior atribuição e menor valor, foram $s_{3}$ vulgar e $s_{5}$ rude, associados àqueles que o narrador indicou não possuírem sangue branco. Portanto, as relações de complementaridade da narrativa encontram-se como posicionados no quadro 3, definindo agradável e suave como complementares a tudo o que a narrativa agrega com a etnia branca, assim como tornam vulgar e rude complementares ao que a narrativa indica como lugarcomum, a etnia preta.

Quadro 3 - Quadrado semiótico com relações de complementaridade.

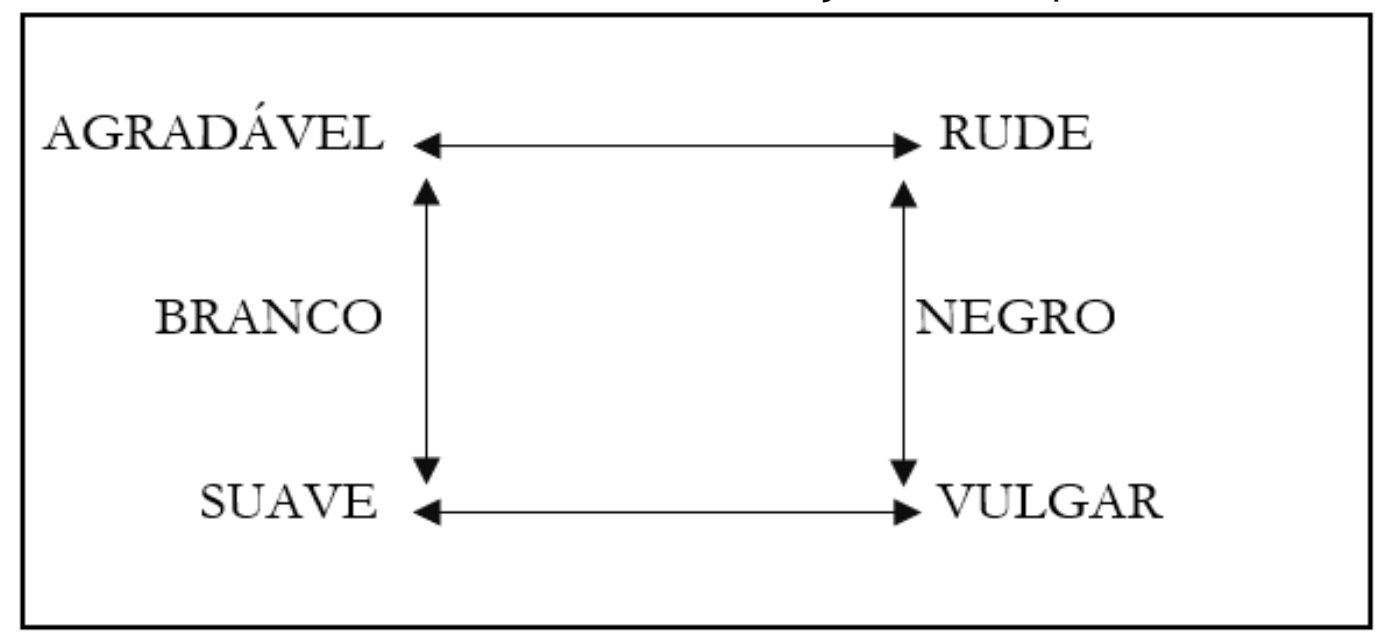

Fonte: Autores (2019).

Logo, resgatando o conceito de Greimas de contradição, sugerimos não agradável $x$ rude, não suave $x$ vulgar, nas relações de contrariedade, pois a ideia de complementaridade é sujeita à de contradição, sendo assim, para o quadrado semiótico, as ideias complementares são apenas válidas se apresentarem 
contradição plausível com as ideias complementares opostas. Ou seja, não agradável é equivalente a rude; não suave é equivalente a vulgar. $E$, nas relações de contradição, agradável x vulgar e suave x rude, como observado no quadro 4.

Quadro 4 - Quadrado Semiótico de Melanctha.

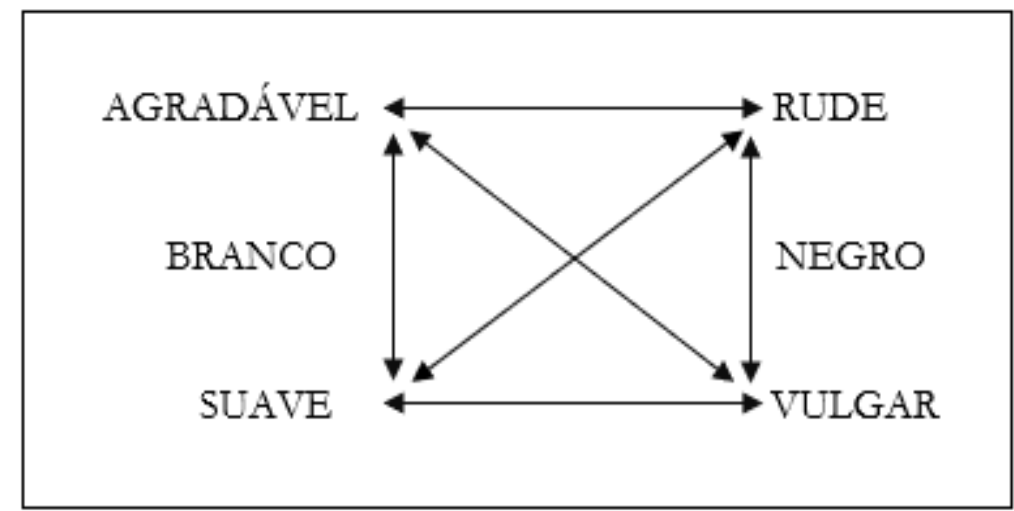

Fonte: Autores (2019).

A repetição em Melanctha (1983) foi indicada por Lucarelli (2013) como padrões de palavras. Para ele, nenhuma palavra possui significado isolado, mas repercute em uma dúzia de relações com outras palavras, pois, "each repetition with variation carries its own emphasis, its own context, and as a 'kind of one', points back to the whole of where it came"4 (LUCARELLI, 2013, p. 2). Em Melanctha (1983), o narrador repete cinco vocábulos com maior ênfase, associando-os à etnia de seus personagens, gerando diferença e, pela repetição, indicam motivo e intenção por parte do narrador, criando, assim, conflito e caracterização entre os mesmos. O narrador tenta atribuir valor moral aos seus personagens por meio da sublimação de personalidade e constante resgate dos signos que reforcem o discurso definido pelo narrador. É, portanto, sintática, a diferença desenvolvida pelo narrador para que o leitor, instintivamente, defina quem supostamente é idôneo ou não em Melanctha (1983). Além disso, o narrador define as personagens que são válidas de tal mérito mediante a etnia, pois acredita nessa prática e reforça estereótipos. Dessa forma, a compreensão de tais signos é essencial para que ocorra o entendimento do nível narrativo pelo leitor, sendo esse profundamente trabalhado com as figuras construídas e inseridas na comunidade negra a qual pertence Melanctha.

\footnotetext{
4 "Cada repetição com variações carrega a sua própria ênfase, o seu próprio contexto, como um "tipo", de pontos de retorno para o conjunto de onde isso veio."

Revista de Letras JUÇARA, Caxias - Maranhão, v. 03, n. 02, p. 173 - 187, dez. 2019 | 184
} 


\section{Considerações finais}

Após décadas de luta para o reconhecimento de negros enquanto pessoas, Melanctha (1983) soa como um retrocesso de ideias, pois agrega aos seus personagens valores negativos, sempre que tenham ligação com o que é não-branco.

O enunciado, desde o seu início, ainda no nível fundamental do sentido, fornece ao enunciatário as ferramentas para que se chegue às conclusões de que há um grupo a ser excluído e, outro, a ser respeitado. A protagonista do enunciado perambula no meio dessas definições fechadas, mesmo que o enunciador a coloque como uma pessoa "quase branca", merecedora das atribuições conferidas a grupo idôneo.

Contudo, quando Melanctha Herbert demonstra ter orgulho da comunidade que integra, pois reconhece a força que provém de seu pai, um negro, e que gosta de conhecer os mistérios que rondam a cabeça e o coração de negros, o enunciador começa a traçar a sua última vingança, desde que alguém que tem a chance de ascender, de sair do limbo social e evoluir para uma, em teoria, comunidade civilizada ou como o enunciador alcunhou, decente, não merece piedade.

Além disso, o enunciado desenvolve a retórica de que negros devem relegar seus costumes, aos seus irmãos, para abraçar a moral branca, pois apenas dessa forma pode-se ter uma vida respeitável, mesmo que seja apenas de aparências; é melhor que se viva uma mentira do que expor a verdade de seus atos. Assim como fornece a perspectiva de que homens sabem o que é melhor para as mulheres e que elas devem ser guiadas por seus pais até que se casem.

Portanto, para uma novela considerada progressista em seu tempo, nada mais é que a reprodução e reforço de estereótipos que tornam o convívio igualitário e o respeito entre pares, independente de etnia, uma utopia, mesmo que se tenham passado 110 anos, desde a sua publicação. Não se pode afirmar qual o propósito de Gertrude Stein quando desenvolveu os alicerces para a construção de Melanctha (1983), ou qual o impacto gostaria de causar, mas, hoje, podemos afirmar que a novela que escreveu é uma faca de dois gumes: ousada para o período, mas superficial e estereotipada para qualquer que seja a época.

\section{BLACKNESS IN SEGREGATION AGE: SEMIOTIC ANALISIS OF MELANCTHA, BY GERTRUDE STEIN}


Abstract: This research result from a project that aims to analyse, on discursive perspective, a novel from Three Lives, by Gertrude Stein, north-american writer. The research objective is to understand how the book separate its characters by their characteristics given to them by their race. The theoretical validity is based by cultural studies dialog, as Woodward (2000) and feminists theories by Bell Hooks $(1981 ; 2000)$ and Angela Davis (1982). To the analysis, we get semiotic theory contribution by Barros (2005) and Fiorin (2008). It privileged the character figure analysis, considering enunciator's syntactic and semantic resources. Melanctha's transitory among assumed benefits by her light skin and her constant search for black community's acceptance where she lives it's what shows the ethnic limbo, the entre-lugar where she is. As final results, we get that its characters not only had racial stereotypes that reminds from slavery where laws and segregation was built among the citizens, but also used post slavery representation which black people were subject by white population, exposed to insulting and subhuman situations, as horrid as slavery.

Keywords: Melanctha. Gertrude Stein. Representation. Identity. Semiotic.

\section{Referências}

ABREU, Andreia Manuela Passos. Gertrude Stein e o Cubismo Literário. Dissertação (Mestrado em Estudos Americanos) - Porto: Universidade Aberta, 2008.

BARROS, Diana Luz Pessoa de. Teoria Semiótica do Texto. 4. ed. São Paulo: Editora Ática, 2005.

CANDIDO, Antonio. A Literatura e a Vida Social. In: . Literatura e Sociedade. 9 ed. Rio de Janeiro: Ouro sobre Azul, 2006. P. 27-50.

CHARTIER, Roger. O mundo como representação. Revista das revistas. São Paulo, v. 11, p. 173-191, 1991.

DANIEL, Lucy. Gertrude Stein. Chippenham: Reaktion Books, 2009.

DAVIS, Angela. Mulheres, raça e classe. São Paulo: Boitempo Editorial, 2016.

ENGLISH, Daylanne K. Unnatural Selections: Eugenic in American Modernism and The Harlem Renaissance. Carolina do Norte: The University of North Carolina Press, 2004.

FIORIN, J.L. Teoria dos signos. In: _ (org.). Introdução à linguística. 4. ed. São Paulo: Contexto, 2005. p. 55-73.

GALE, Thomas. (org.). Melanctha: Short Stories for Students. Minnesota: The Gale Group, 1999.

HOOKS, Bell. Feminism is for everybody. Cambridge: South End Press, 2000. 
LUCARELLI, Jason. Using Everything: Pattern Making in Gertrude Stein's Melanctha, Robert Walser's Nothing at All", and Sam Lipyte's "The Wrong Arm". Número Cinq. 12 Ago 2013. Disponível em: <http://numerocinqmagazine.com/2013/08/12/usingeverything-pattern-making-in-gertrude-steins-melanctha-robert-walsers-nothing-at-alland-sam-lipsytes-the-wrong-arm-essay-jason-lucarelli/> Acesso em: 20 Jun 2017.

KARNAL, Leandro. (et al). História dos Estados Unidos: das origens ao século XIX. São Paulo: Contexto, 2007.

MALCOLM, Janet. Duas Vidas: Gertrude e Alice. São Paulo: Paz e Terra, 2008.

SANTAELLA, Lucia. Semiótica Aplicada. São Paulo: Pioneira Thomsom Learning, 2005.

SILVA, Alcione Leite da; LAGO, Mara Coelho de Souza; RAMOS, Tânia Regina Oliveira. (org.). Falas de Gênero. Santa Catarina: Editora Mulheres, 1999.

SILVA, Tomaz Tadeu. (org.). HALL, Stuart; WOODWARD, Kathryn. Identidade e diferença: a perspectiva dos Estudos Culturais. 15. ed. Rio de Janeiro: Vozes, 2014.

SOUZA, Marcos Aurélio dos Santos. O entre-lugar e os estudos culturais. Travessias, Cascavel. v. 1, n.1, p. 1-13, 2007.

STEIN, Gertrude. A autobiografia de Alice B. Toklas. São Paulo: Cosac Naify, 2009.

STEIN, Gertrude. Três Vidas. Rio de Janeiro: Nova Fronteira, 1983.

WARE, Vron. (org.). Branquidade: Identidade branca e multiculturalismo. Rio de Janeiro: Garamond: 2004.

WILL, Barbara. Gertrude Stein, Modernism, and the Problem of "Genius". Edinburgh: Edinburgh University Press, 200. 
Data da Submissão: $15 / 11 / 2019$

Data da Aprovação: 18/12/2019 